\title{
Rare Inferolateral Type of Third Head of Biceps Brachii Coexisting with Triple Roots of Median Nerve
}

\section{Deepika, Wadhwa S*, Mahajan A and Mishra S \\ Department of Anatomy, Maulana Azad Medical College, India}

*Corresponding author: Dr Surbhi Wadhwa, Department of Anatomy, Maulana

Azad Medical College, New Delhi, India, Tel: 9818375337; E-mail:

\section{Case Report}

Volume 1 Issue 3

Received Date: November 21, 2017

Published Date: December 04, 2017

wadhwa.surbhi@gmail.com

\section{Abstract}

The current report is unique as it highlights the coexistence of triple roots of median nerve, three heads of biceps brachii muscle and communicating branches from musculocutaneous nerve to median nerve in right brachium of an Indian male cadaver. The extra root of median nerve needs to be kept in mind while performing interventions in the shoulder region. The communication between musculocutaneous nerve to median nerve in arm may be beneficial in cases of median nerve injury in axilla. The supernumerary head of biceps brachii may be a potential cause of neurovascular compression and dislocation during humeral shaft fracture. The knowledge of such variations may be especially advantageous to radiologists, orthopaedic surgeons and neurosurgeons.

Keywords: Biceps brachii; Median nerve; Musculocutaneous nerve; Communication

Abbreviations: MN: Median Nerve; MCN: Musculocutaneous Nerve; LR: Lateral Root; C: Communicating Branch

\section{Introduction}

The median nerve (MN) arises from two roots-medial and lateral, which encircle the third part of axillary artery and unite anterior or lateral to it to form the main trunk of MN. The musculocutaneous nerve (MCN) is the continuation of lateral cord of brachial plexus. It gives motor branch to coracobrachialis about $2 \mathrm{~cm}$ below the tip of coracoid process. The MCN then pierces coracobrachialis after which it gives motor branches to biceps brachii and brachialis. It pass downward and laterally between brachialis and biceps brachii, gives a branch to humerus and continues as lateral cutaneous nerve of the forearm.
The biceps brachii, a muscle of the anterior compartment of brachium, is the main supinator when elbow flexed and powerful flexor of elbow joint, it also assists in flexion at shoulder joint. The muscle derives its name from two proximally attached tendinous heads - the proximal attachment of short head is on the apex of coracoid process of scapula while the long head begins as a long tendon from supraglenoid tubercle of scapula which lies within the cavity of shoulder joint. They exhibit tendinous insertion on the rough posterior part of the radial tuberosity. From the tendon arises a bicipital aponeurosis which inserts into the fascia over the origin of flexors of forearm [1].

\section{Case Report}

While exploring the branches of brachial plexus during routine undergraduate cadaveric dissection teaching sessions an extra root of $\mathrm{MN}$, communicating branch from 
MCN to MN and an accessory head of biceps brachii were noticed in the right upper limb of a 63 years old formalin embalmed adult male cadaver of Indian origin. All the variations were photographed and recorded. The other side of the body was found to be normal.

While delineating the lateral cord of brachial plexus in axilla, we noticed variation in the formation of MN. The MN was formed by union of three roots-two from the lateral cord and one from the medial cord of brachial plexus. The lateral cord gave a branch, which was lateral root of MN (LR1). This crossed the second part of axillary artery anteriorly from lateral to medial side to unite with the medial root of $\mathrm{MN}$, medial to the axillary artery. Thereafter another branch (LR2) emerged from the lateral cord in the axilla, $3.2 \mathrm{~cm}$ from the coracoid tip. This branch (LR2) coursed infero-medially to unite with the MN $4 \mathrm{~cm}$ distal to the site of union of medial and lateral root (LR1), this branch (LR2) represented the third root of MN (Figure 1a \& 1b).

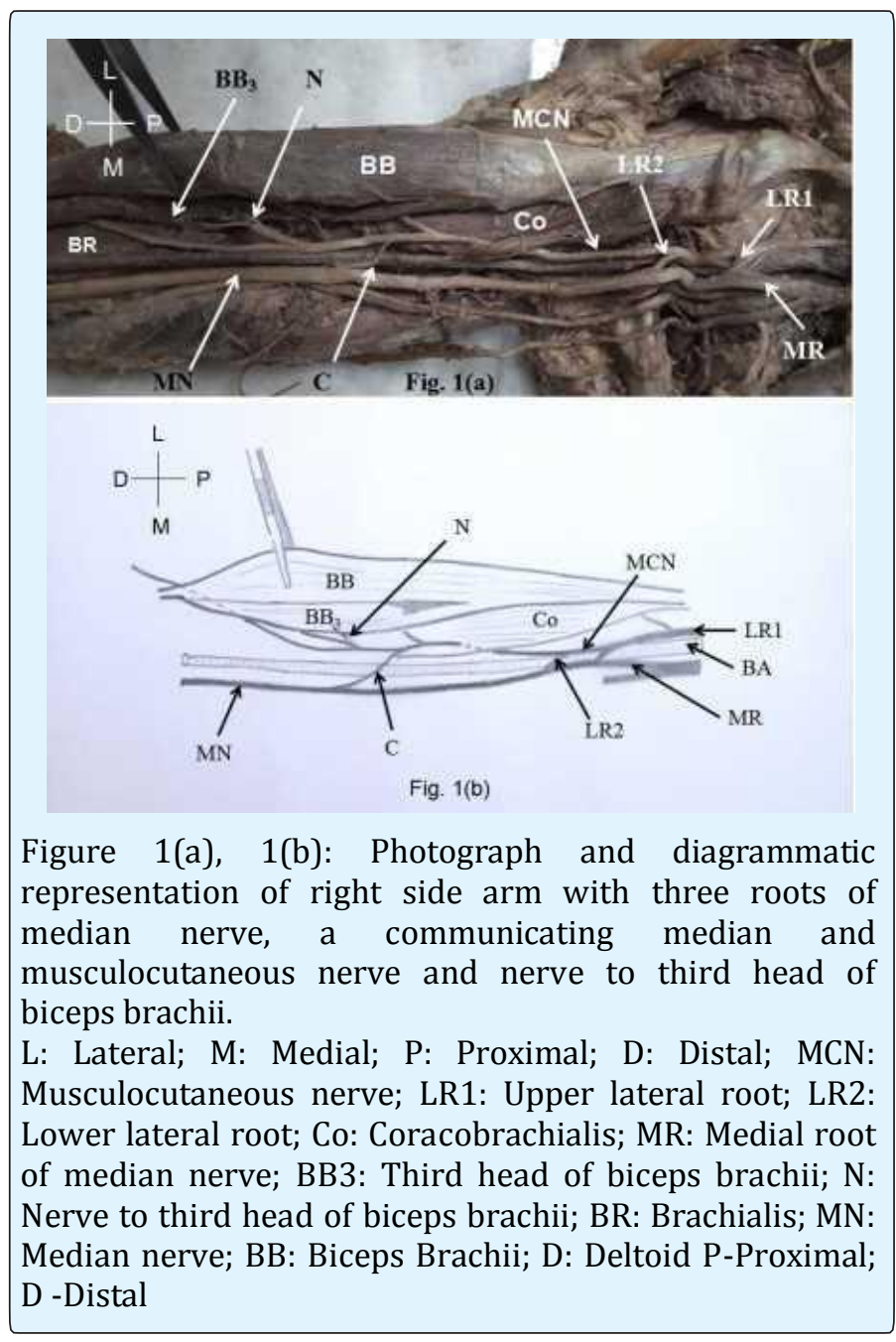

In the middle one-third of the brachium, MCN gave an anomalous branch at a distance of $13.6 \mathrm{~cm}$ from the tip of coracoid process which crossed the brachial artery anteriorly from lateral to medial side and joined the MN $13.5 \mathrm{~cm}$ distal to the commencement of MN. This was the communicating branch (C) between MCN and MN.

Further while exploring the muscles in the anterior compartment of arm we noticed an anomalous muscle $\left(B_{3}\right)$ originating from the anterolateral surface of the humeral shaft at the level of insertion of deltoid laterally and coracobrachialis medially (Figure 2a \& 2b). The muscle fibers of $\mathrm{BB}_{3}$ merged with the fibers of short head of biceps brachii near the lower end of humerus. The common tendon crossed the elbow joint to get attached to the posterior surface of radial tuberosity. This muscle $\left(\mathrm{BB}_{3}\right)$ was the third head of biceps brachii with fleshy origin from anterolateral aspect of humeral shaft unlike the other two heads which had tendinous origin from scapula. Unlike the other two heads if biceps which were innervated by direct branches of $\mathrm{MCN}, \mathrm{BB}_{3}$ was indirectly innervated through nerve to brachialis.

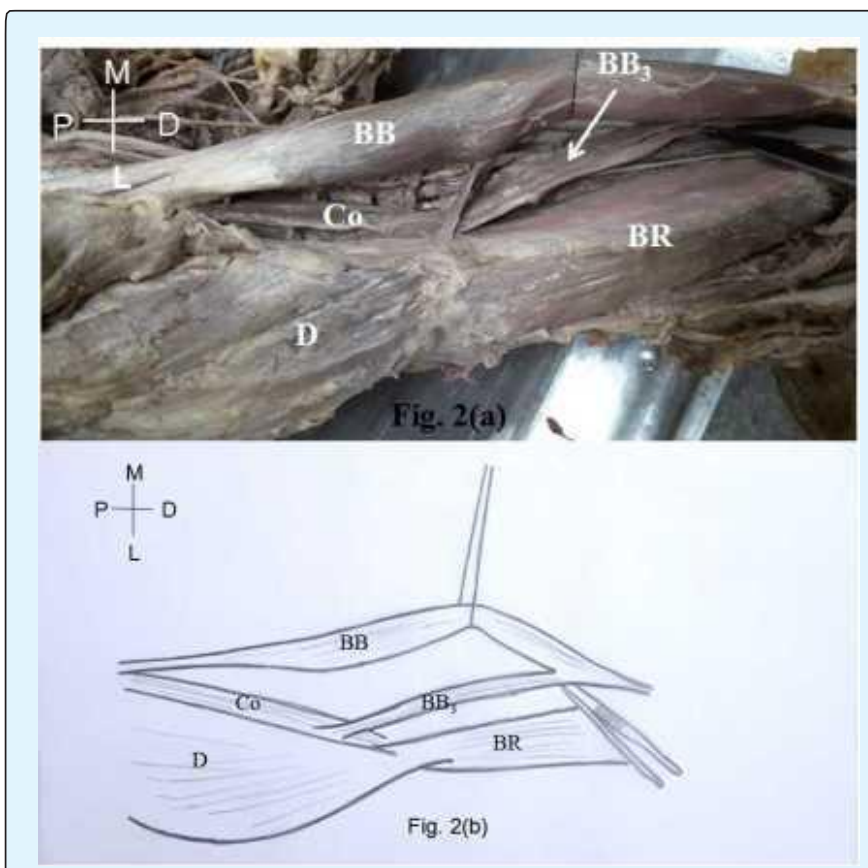

Figure 2(a), 2(b): Photograph and diagrammatic representation of third head of biceps brachii originating from anterolateral surface of humerus, at the level of insertion of deltoid and coracobrachialis. It joins the belly of biceps brachii on deeper plane just above the elbow joint.

M: Medial; L: Lateral; D: Distal; P: Proximal; BB: Biceps brachii; Co: Coracobrachialis; D: Deltoid; BB3: Third head of biceps brachii; BR: Brachialis. P-Proximal; D -Distal 


\section{Discussion}

In the present case we found multiple variations on right side which included-anomalous formation of $\mathrm{MN}$, communicating branch between MCN and MN and extra head of biceps brachii. The $\mathrm{MN}$ was formed by three roots-two from lateral cord and one from medial cord. A communicating branch carried the fibres from MCN to MN in the middle-third of the arm. The third head of biceps brachii originated from antero-lateral surface of humeral shaft at the level of insertion of deltoid and coracobrachialis. The third head of biceps brachii was indirectly innervated by MCN through nerve to brachialis.

The brachial plexus develops from a single growth cone of spinal nerve axons under the influence of random growth factors. This growth cone divides into ventral and dorsal divisions. The $\mathrm{MN}$ and MCN are derivative of ventral division. The MCN emerges as a branch from the MN. The variations seen may be the result the incoordination between the growth cone and growth factors [2]. Saeed et al. [3] explained the existence of communicating branch between $\mathrm{MN}$ and MCN to be the effect of neurobiotaxis during embryonic life.

The additional root of MN must be of concern for surgeons operating in axilla, if overlooked the nerve fibers may get accidently damaged. The communicating branch between MCN and MN may be beneficial for cases with median nerve injury, preserving the nerve fibers which hitch-hike along with MCN and join the MN distal to the site of nerve injury. The communicating branch may get compressed in the arm during application of cuff resulting in paraesthesia in distal part of limb.

The unusual formation of MN with third root from the lateral cord have been reported earlier by researchers [25]. However, they reported the thickness of lower lateral root to be more than upper lateral root. In the present case both the lateral roots are apparently equal in thickness (LR1=2.126mm, LR2=2.115mm).

The additional root of MN and supernumary heads of biceps brachii muscle were also reported by Ongeti, et al. [5]. In their case the third root of $\mathrm{MN}$ was present the mid-arm. In our report the third root of median nerve is located in axilla and needs to be borne in mind while performing at greater risk of damage during axillary lymph node excision.

The incidence of third head of biceps brachii has been studied in different races. Kosugi, et al. found it to be $13.7 \%$ in Japanese population, Asvat, et al. reported it to be $20.50 \%$ in South African population while Lokanadham S, et al. found incidence to be only $5 \%$ in the South Indian population. The data indicates the rare existence of third head in Indian population [6-8].

According to Standring S, third head may originate from the superomedial aspect of brachialis which inserts on the bicipital aponeurosis and medial aspect of the tendon of biceps brachii. Rarely the fibers may arise from the anterolateral surface of humerus. The muscle derives nerve supply from MCN with separate branch for each head [1]. The present cadaver displayed origin of anomalous head of biceps brachii from anterolateral surface of humerus however in contrary to the standard text book; it was not directly innervated by MCN but indirectly through nerve to brachialis.

Supernumerary heads of biceps brachii were classified by Rodriguez-Niedenfuhr, et al. on the basis of origin and location as-superior, inferomedial and inferolateral types. According to them inferomedial type is the most prevalent, arises from the anteromedial surface of humeral shaft between distal attachment of coracobrachialis and proximal attachment of brachialis. The current cadaveric finding resembles "Inferolateral" type which is uncommon variety according to RodriguezNiedenfuhr, et al. [9].

The emergence of the supernumerary head of any muscle, may be the result of longitudinal splitting of primordial muscle mass destined to form a parent muscle, as explained by McMurrich. Hence the nerve supply to the additional head is from the branch of the nerve supplying the parent muscle [10]. In the present report, the third head of biceps brachii procured its nerve supply from nerve to brachialis, which implies that the variant head initially during intra-embryonic life was part of brachialis muscle which later as a result of splitting of its primordial muscle mass moved towards biceps brachii. Hence the action of the third head of biceps would be powerful flexor at elbow joint, similar to the action of its parent muscle brachialis.

\section{Conclusion}

The awareness of the variant extra root of $\mathrm{MN}$ and communicating branch between MCN and MN holds significance for neurosurgeons, orthopaedic surgeons and physiotherapists. The branching patterns of the nerves forming brachial plexus must be known to a surgeon preoperatively when planning nerve grafting, brachial plexus repair, selective motor nerve block for a muscle or when performing regional nerve block. The additional 
head of biceps brachii may lead to variable displacement of fractured bone and hence necessitate the earlier reduction to prevent abnormal dislocation. The knowledge about the supernumerary head of muscle and its innervations is prerequisite for flap surgery when using biceps brachii as donar.

\section{References}

1. Standring S (2016) Gray's Anatomy: The Anatomical Basis of Clinical Practice. 41 ${ }^{\text {st }}(\mathrm{edn})$, Elsevier Churchill Livingstone, New York.

2. Iwata H (1960) Studies on the development of the brachial plexus in Japanese embryo. Rep Dept Anat Mie Prefect Univ Sch Med 13: 129-144.

3. Saeed M, Rufai AA (2003) Median and musculocutaneous nerves: Variant formation and distribution. Clin Anat 16(5): 453-457.

4. Das S, Paul S (2005) Anomalous branching pattern of lateral cord of brachial plexus. Int J Morphol 23(4): 289-292.
5. Ongeti K, Pulei A, Ogeng'o J, Saidi H (2012) Unusual formation of the median nerve associated with the third head of biceps brachii. Clin Anat 25(8): 961-962.

6. Kosugi K, Shibata S, Yamashita H (1992) Supernumerary head of biceps brachii and branching pattern of the musculocutaneous nerve in Japanese. Surg Radiol Anat 14(2): 175-185.

7. Asvat R, Candler P, Sarmiento EE (1993) High incidence of the third head of biceps brachii in South African populations. J Anat 182(pt 1): 101-104.

8. Lokanadham S, Subhadra Devi V (2011) Unusual presentation of supernumerary heads of Biceps brachii in South Indian Population. World Journal of Medical Sciences 6(3): 115-120.

9. Rodriguez-Niedenfuhr M, Vazquez T, Choi D, Parkin I, Sanudo JR (2003) Supernumerary humeral heads of the biceps brachii muscle revisited. Clin Anat 16(3): 197-203.

10. McMurrich, James Playfair (1923) The Development of the Human Body. $7^{\text {th }}$ (edn), McGraw Hill Company, New York, pp: 507. 